\title{
Promising Practice
}

\section{Lessons Learned from Online PLCs of Rural STEM Teachers}

\author{
Tony Durr \\ Jennifer Kampmann \\ Patrick Hales \\ Larry Browning
}

This article details a Title II grant funded professional development project for rural STEM teachers. For this project teachers were grouped in online professional learning communities (PLCs). Participants shared teaching videos and received feedback from their group members and university faculty. In a face-to-face workshop, participants were trained on how to effectively record and share videos with their PLC group. After the workshop, all communication was conducted through digital means. During this project we learned that the frequency of video posting, the type of videos posted, and the style of reflection questions, were critical aspects to the engagement of participating teachers. Additionally, teachers showed an increase in teacher efficacy as a result of being part of the online PLCs and they indicated strong enjoyment and value in participation of the program.

As part of a Title II grant initiative, a team of faculty at a mid-western university, designed a professional development experience for rural STEM teachers. The proposal of the grant was to enrich the content knowledge of STEM teachers, specifically in the cross-cutting concepts of the Next Generation Science Standards (NGSS), and to create professional learning communities (PLCs) among rural teachers. In addition to developing increased content knowledge, this project focused on connecting rural STEM educators that would otherwise be isolated. In many rural South Dakota schools, there are very few, or in some cases, only a single teacher for each content area. Rural schools in South Dakota can be separated not only in distance but in the lack of cohort colleagues of like disciplines. For example, one of the high school chemistry teachers in this study is 292 miles from any other content-alike teacher or colleague. An average distance in this study from teacher to teacher was 200 or more miles. This can present rural teachers with a sense of isolation and lack of professional development opportunities. This type of isolation and need of support has been shown to negatively impact retention, performance, and other aspects of teaching (Gammon, Hutchison, Waller, and Tolbert, 1999; Lauer et al, 2005; Sealander et al., 2001)

The aim of the project was to utilize technology to create online PLCs which connected teachers to both each other and to university content and pedagogical experts. These PLCs would combat feelings of isolation through a focused reflection on content standards and teaching practices.

\section{Literature Review}

Rural teachers are often isolated and disconnected from colleagues, particularly in their own content area. There are effective examples of rural teachers developing professional networks, specifically in their content areas, the Northwest Rural Innovation and Student Engagement (NW RISE) network is one (Johnston et al., 2018). However, the literature indicates that, in general, professional development and professional communities are a struggle for many rural teachers.

There is evidence that, despite extensive literature, (Darling-Hammond et al., 2009; Desimone, 2009; Schlanger \& Fusco, 2003; Stillman, 2011), the public education system is still falling far short of effective professional learning (Center on Education Policy, 2013; Darling-Hammond et al., 2009). Many teachers report their professional development experiences as weakly aligned and formulaic, poorly organized, sporadic, and un-engaging (DarlingHammond et al., 2009; Lieberman \& Pointer Mace, 2008; OECD, 2014 Vescio et al., 2008; Watson, 2014).

Most professional development takes place in the one-time, motivational speaker-style, workshop 
setting which don't promote long-term instructional improvement (Borko, 2004; Darling-Hammond et al., 2009; Desimone, 2009; Van Driel \& Berry, 2012).

One review of 1,300 professional development studies found that programs lasting less than fourteen hours had little effect on instruction and no effect on student achievement (Yoon, Duncan, Lee, Scarloss, \& Shapley, 2007).

\section{Online PLCs}

Hord and Sommers (2008) explain "that PLC is not just working together on carefully identified tasks but supporting that work through careful study and learning of relevant subject matter" (p. xiii). Research has indicated that the structure of the participants conversations can have a strong impact on the effectiveness of the PLC group (Horn \& Little, 2010; Fataar \& Feldman, 2016). In this project, the emphasis on NGSS and the development of teaching practice, with the guidance of university faculty, provided the groups with a focus. Also, a great deal of attention was paid to the development and refinement of the communication structure of the PLCs.

A study conducted on teacher professional learning online by Dede and colleagues (2009) warned that disjointed modules of information posted online void of discussion and collaboration yielded an implementation gap (Borko, 2004) where teachers were not able to put their professional learning into practice. Creating online learning communities for teachers is not about adding technology to learning communities; rather, it means creating and supporting a process which is purposeful, flexible, and continuous and develops teacher content and pedagogical knowledge (Lock, 2006).

\section{Background}

The project began with a three-day orientation and training workshop. Table 1 , below, provides a brief outline of the activities.

This training workshop took place in early August of 2017, a few weeks before a solar eclipse. Therefore, many of the sample lesson activities activities provided teachers with project ideas to help their students observe and study the celestial event. For example, one project included the creation of solar telescopes and another explored pinhole cameras. Participants left with detailed plans and materials to replicate the labs in their own classrooms. They could then reflect on how the lesson worked in their online PLCs.

Table 1

Outline of Orientation Activities

\begin{tabular}{ll}
\hline & \multicolumn{1}{c}{ Day 1 } \\
\hline 9:00-9:30 & Welcome and Introductions \\
9:30-10:30 & PLC Norms and Group Formation \\
10:30-12:00 & Technology Introduction and Practice \\
12:00-1:30 & Lunch and Video Assignment \\
1:30-3:00 & Introduction to NGSS Standards \\
3:00-4:30 & Use of Technology for Video Reflection \\
4:30-5:00 & Recap and Reflection \\
\hline & $\quad$ Day 2 \\
\hline 9:00-9:30 & Opening \\
9:30-12:00 & NGSS Aligned Lesson Demonstrations \\
12:00-1:30 & PLC Group Lunch \\
1:30-4:30 & Collaborative NGSS Lesson Creation \\
4:30-5:00 & Recap and Reflection \\
\hline & \\
\hline 9:00-9:30 & Opening Day 3 \\
9:30-12:00 & Practice Video Sharing and Online Reflective Feedback \\
12:00-1:30 & Schedule for Lesson Sharing \\
1:30-4:30 & Collaborative NGSS Lesson Creation \\
4:30-5:00 & Recap and Reflection \\
\hline
\end{tabular}

Vol. 41, No. $1 \quad$ The Rural Educator, journal of the National Rural Education Association 


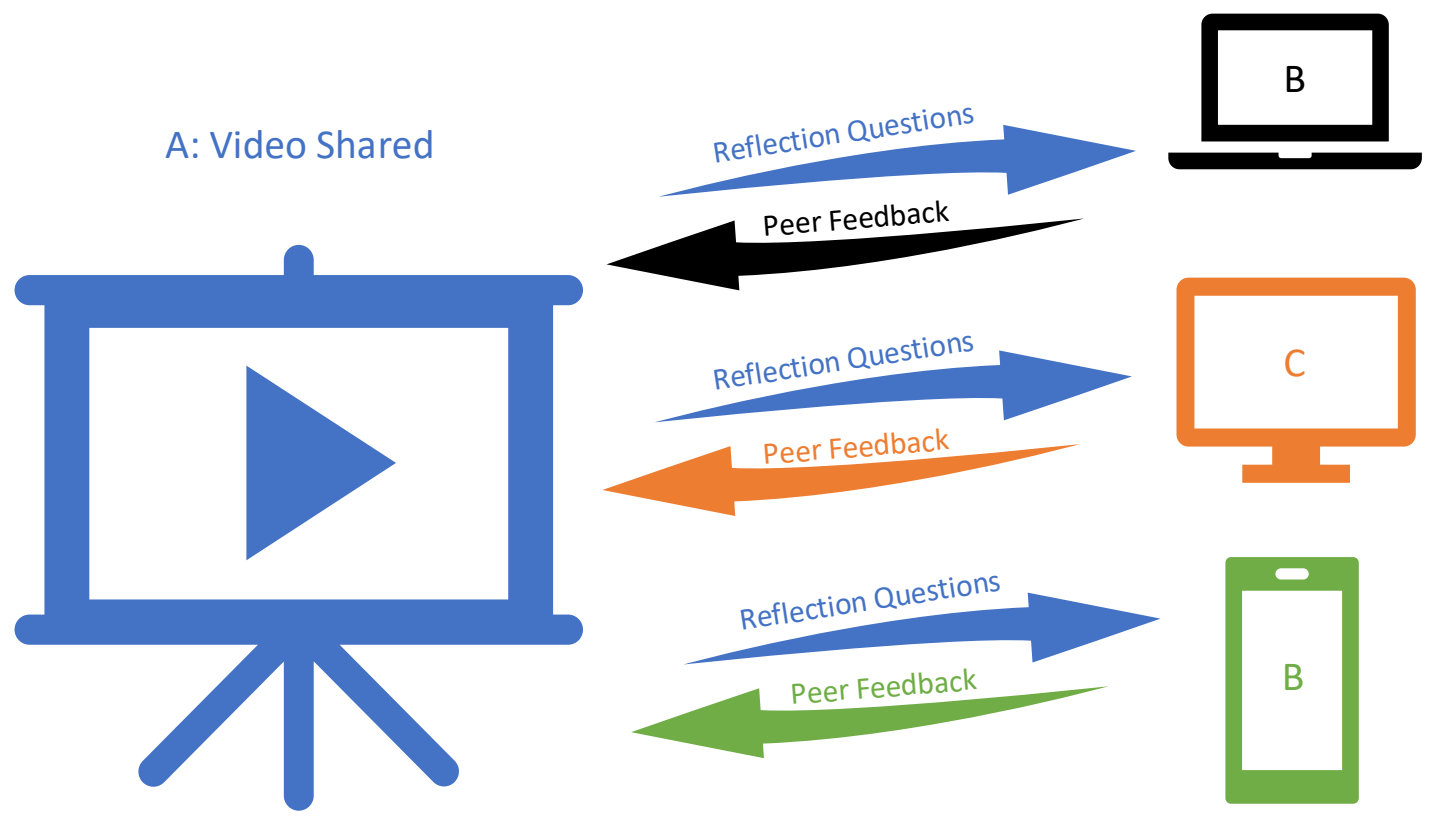

During the final day of the workshop, participants completed a full dry run of the lesson sharing and discussion process. This process included: 1) Record a teaching video. 2) Upload it to Youtube and sharing the video with the project facilitators. 3) After the facilitators placed the video on the PLC's video discussion board, the teachers provided video feedback. 4) Participants could then view and reply to feedback from peers.

Figure 1 is an illustration of the video sharing and communication process of a PLC group (group members labeled as: A, B, C, and D).

One example of these exchanges was when a teacher shared a lesson on density, then on the group's video discussion board she asked her PLC group members for feedback on her implementation of discovery-based questions. One group member gave feedback pertaining to the language being used, providing specific suggestions like telling the teacher to ask her students to "design a model" rather than "draw a picture." Another group member provided feedback by sharing struggles he experienced with his students when teaching buoyancy as it relates to density.

These types of exchanges occurred every few weeks as teachers took turns sharing lessons and soliciting feedback. The project began with two PLC groups, each with 4 members. For the purpose of this article we will refer to these groups as PLC \#1 and PLC \#2. Partway through the project an additional PLC \#3 group was added and more details about this group will be provided later.

\section{Findings}

The initial engagement of the PLC participants was disappointing. Specifically, PLC \#1 members posted three lesson videos during the first three months of the project, but no additional lesson videos were shared during the remaining five months. Additionally, PLC \#1 members provided limited feedback in their response videos. During the first month, two of the three responding members provided feedback on the reflection questions. In the second month, only one group member provided feedback. In the third month, no feedback from group members was provided.

PLC \#2 was more engaged than PLC \#1, but their activity was still disappointing. As can be seen in Table 2, only half of the expected lesson videos were shared with the PLC and less than half of the expected feedback responses were provided by members of the group.

Much was learned during the first months of this project regarding the engagement of the participants, 
Table 2

Participation Comparison across PLC Groups

\begin{tabular}{lccc}
\cline { 2 - 4 } & PLC \#1 & PLC \#2 & PLC \# 3 \\
\hline Percentage of expected lesson video shared. & 3 out of $8=37.5 \%$ & 4 out of $8=50 \%$ & $100 \%$ \\
Percentage of expected peer responses made. & 3 out of $9=33 \%$ & 5 out of $12=41.7 \%$ & $100 \%$ \\
\hline
\end{tabular}

which informed the creation of the third PLC group. Things we changed:

- More frequent video postings.

- Simplification of the response process.

- Streamlining the video sharing process with shorter lesson artifact videos.

Similar, to the initial training workshop, PLC \#3 completed an in-person training workshop. However, this workshop was completed in only one day and included one PLC group of 4 STEM teachers. The morning was dedicated to introduction of the project, iPads were distributed, and participants were trained on how to record and share lesson videos. During the afternoon, participants completed science labs that could be recreated for students in their own classrooms. The workshop concluded with a trial run of the video sharing and feedback process.

These changes seemed to have a drastic effect on the engagement of the PLC members. As can be seen in Table 2, PLC \#3 group member shared all the expected lesson videos and made all the expected feedback responses. PLC \#3 actually gained a fifth group member during the project. One member of PLC \#1 was frustrated with the lack of interaction in her PLC and contacted the project fascinators to voice her concern. She was then moved to PLC \#3 and became their fifth group member.

The participation and engagement of the PLC \#3 group members had positive outcomes. Specifically, the teachers reported an increase in their sense of efficacy during the project. The teachers' sense of efficacy scale (TES) measures a teacher's confidence or efficacy across three factors, student engagement (i.e. how much can you do to motivate students who show low interest in school work), instructional strategies (i.e. to what extent can you craft good questions for your students), and classroom management (i.e. how much can you do to control disruptive behavior in the classroom). The instrument has been widely used and is a validated measure of teacher efficacy (Tschannen-Moran \& Woolfolk Hoy, 2001). Of the five PLC \#3 group members four completed the TES survey both before the project began and after it concluded. Due to the small number of participants statistical significance tests are ineffective. However, reviewing the data for each participant, it is clear that the sense of efficacy increased for each teacher in each factor, with the exception of one participant in the area of student engagement. Table 3 illustrates this growth.

With one exception, this data indicates that each participant's sense of efficacy increased across this project. It is possible that this increase can be attributed to other factors, for example, the teachers' efficacy may have increased during the school year because of more developed relationships with students or due to some other variable. However, when this data is combined with comments from the participants, the positive impact of the PLC is clear. For example, in the concluding survey one participant commented, "It was very helpful to see other teachers in the same content areas in their classroom environment and share ideas and concerns." Another stated the most helpful aspect of the project was, "receiving input for both things that worked well and how to change things up to make them better." It is worth noting that, unsolicited,

Table 2

Participant Efficacy Growth

\begin{tabular}{lccc} 
& $\begin{array}{c}\text { Percent increase: efficacy in } \\
\text { student engagement. }\end{array}$ & $\begin{array}{c}\text { Percent increase: efficacy in } \\
\text { instructional strategies. }\end{array}$ & $\begin{array}{c}\text { Percent increase: efficacy in } \\
\text { classroom management. }\end{array}$ \\
\hline Participant 1 & $3.57 \%$ & $3.23 \%$ & $9.68 \%$ \\
Participant 2 & $0.00 \%$ & $8.00 \%$ & $7.14 \%$ \\
Participant 3 & $30.43 \%$ & $13.33 \%$ & $14.29 \%$ \\
Participant 4 & $32.00 \%$ & $6.67 \%$ & $12.00 \%$ \\
\hline
\end{tabular}

Vol. 41, No. 1 The Rural Educator, journal of the National Rural Education Association 
several participants inquired about continuing the project into the next school year. When asked about concerns or frustrations, the most common response from participants was time constraints and/or technology struggles.

\section{Lessons Learned}

During this project we learned a great deal about how to design and support online PLCs. Specifically, we identified the following critical elements: more frequent video postings, video artifacts instead of full-length lessons, and a simplified reflection process.

\section{Frequent Video Postings}

The initial training workshop took place in August. Since the PLC teachers had not yet begun their school year, the initial video sharing was not scheduled until a month later. This one-month lag caused the PLC participants to become disconnected. The participants forgot some of the technological steps in the video recording and sharing process and required reminders on the process, as well as the specifics of the reflection questions. PLC \#3, however, began their video sharing 11 days after their training workshop. The quick turnaround helped keep the project and technological details fresh in the teachers' minds. New lesson videos were shared every two weeks, rather than every month, which helped the PLC members to develop a habit of sharing, viewing, and commenting on video lessons.

\section{Video Artifacts}

The video lessons were originally intended to be full lesson artifacts, which typically amounted to around 50-minute lessons. Videos of this length were sometimes more difficult to share and upload because of the larger file size and the time commitment to review these lessons for the PLC members was burdensome. We solicitated feedback from the PLCs on how to improve the project and the length of videos was a point of concern, in particular for the more engaged and later starting PLC \#3. So, beginning in January the video artifact expectation was amended. PLC participants in all groups were asked to create 15-minute videos that "captured" the lesson. The teachers were encouraged to create more engaging videos. For example, it was suggested that teachers assign a student to be a video journalist for the lesson and to create a news styled report on the content of the lesson. These streamlined video artifacts required less time to review and provided a better representation of students' experiences. For example, initial full-lesson videos often had a 'camera in the back of the room' vantage point, which provided limited details of the lesson. It was difficult to see what exactly students were working on and the audio made it difficult to hear student comments. In creating the shorter video artifacts, teachers were encouraged to move the camera around and record student work and conversations. The journalistic style included some focused student interview questions that provided more intimate and complete information about what the students were learning and how they felt about the lesson.

\section{Simplified Reflection Process}

There was a STEM focus for this Title II grant funded project, which is why we originally asked that all group members reflect on the cross-cutting concepts piece of the NGSS. In addition, participants reflected on student engagement and a third selfselected topic. Initially, we believed these three distinct points of reflection would support more focused, deliberate, and meaningful reflection. In practice, however, it was burdensome on the participants. It required PLC members to provide three different video responses to each lesson, which took more time and effort and often the three responses were repetitive. Once the project switched to a single reflection response, the video feedback was more efficient and effective. Participants indicated the process was more organized and that feedback was clearer and more meaningful.

\section{Conclusion}

In summary, the PLCs that were created in this project did help connect and support rural STEM teachers. Video lesson sharing was best when it was shared frequently and when videos where short artifacts of a teaching lesson. Additionally, PLC members appreciated simplified reflections that allowed them to share feedback that was more personal. Specifically, for the PLC \#3 group, the experience was positive. Participants reported enjoying the project and felt it added value to their classrooms. The teachers also reported an increase in efficacy in student engagement, instructional strategies, and classroom management during the project. 
There are obstacles to implementing this process in rural environments, some which we encountered and others we can anticipate. Technology infrastructure is of primary concern. Many rural environments do not have stable internet connections with which to upload quality video to the cloud. There is also an issue of access and training with regard to technology. Some rural educators do not have access to devices to capture video and take part in discussions nor do they have training to use said technology. Any group, team, or district hoping to take part in the sort of work we present here should conduct assessments of their technology and the knowledge of the participants in order to prepare for these kinds of obstacles.

Another consideration that should be essential to implementing this kind of program is that of fit. The participatory nature of our development of this program was key to its success. Rural environments are sometimes isolated, some more than others, and this carries with it a unique culture and needs that center on that community. No implementation of this program can be "one-size-fits-all." In other words, discussion with the participants about the types of questions that should be asked, what should be recorded, and what each educator wants to learn must take place.

From our experience, online PLCs can be a productive and powerful way to connect rural teachers to one other. Future research and PLC development programs should focus on the development of topics and discussion questions for teachers, particularly with a consideration of community building and rural district needs. This particular project made significant progress and developing logistical details of how to effectively engage rural teachers in online PLCs, but much more can be learned regarding how to maximize teacher development and ultimately student learning.

\section{References}

Borko, H. (2004). Professional development and teacher learning: Mapping the terrain. Educational Researcher, 33(8), 3-15.

Center on Education Policy (CEP). (2013). Year three of implementing the Common Core State Standards: Professional development for teachers and principals. Retrieved from http://www.cep-dc.org/

Close, E. W., Scherr, R. E., Close, H. G., \& McKagan, S. B. (2012). Development of proximal formative assessment skills in videobased teacher professional development. Physics Education Research Conference, 1413(2012), 19-22.

Darling-Hammond, L., Wei, R.C., Andree, A., Richardson, N., \& Orphanos, S. (2009). Professional learning in the learning profession: A status report on teacher development in the U.S. and abroad. Dallas, TX: National Staff Development Council.

Dede, C., Ketelhut, D. J., Whitehouse, P., Breit, L, \& McCloskey, E. M. (2009). A research agenda for online teacher professional development. Journal of Teacher Education, 60(1), 8-19.

Fataar, A., \& Feldman, J. (2016). Dialogical Habitus Engagement: The Twists and Turns of Teachers' Pedagogical Learning within a Professional Learning Community. Perspectives in Education, 34(3), 98-105.
Gammon, S. D., Hutchinson, S. G., Waller, B. E., \& Tolbert, R. W. (1999). The Idaho k- 8 teacher network project: Using the Internet to improve k8 science instruction. Journal of Chemical Education, 76(5), 708-713.

Hord, S. M., \& Sommers, W. A. (2008). Leading professional learning communities: Voices from research and practice. Thousand Oaks, CA: Corwin.

Horn, I. S., \& Little, J. W. (2010). Attending to Problems of Practice: Routines and Resources for Professional Learning in Teachers' Workplace Interactions. American Educational Research Journal, 47(1), 181-217.

Johnston, C., Min Jung Kim, Martin, K., Martin, M., Shirley, D., \& Spriggs, C. (2018). Rural teachers forging new bonds--and new solutions. Educational Leadership, 76(3), 56.

Lauer, P. A., Stoutemyer, K. L., and Van Buhler, R. J. (2005). The McREL rural technology initiative: Research and evaluation study. MidContinent Research for Education and Learning: Aurora, CO. (ERIC Document Reproduction Service No. ED486628)

OECD (2014). TALIS 2013 results: an international perspective on teaching and learning. Washington, DC: OECD Publishing.

Sealander, K., Eigenberger, M., Peterson, P., Shellady, S., \& Prater, G. (2001). Challenges 
facing teacher educators in rural, remote, and isolated areas: Using what we know and what we have learned. Rural Special Education Quarterly, 20(1-2), 13-21.
Yoon, K. S., Duncan, T., Lee, S. W., Scarloss, B., \& Shapley, K. L. (2007). Reviewing the evidence on how teacher professional development affects student achievement. Washington, DC: U.S. Department of Education.

\section{Authors:}

Tony Durr is an Assistant Professor at South Dakota State University. Contact: tony.durr@icloud.com

Jennifer Kampmann is an Assistant Professor and Assessment Coordinator at South Dakota State University. Contact: jennifer.kampmann@sdstate.edu

Patrick Hales is an Assistant Professor and Secondary Teacher Educator Program Coordinator at South Dakota State University. Contact: Patrick.Hales@sdstate.edu

Larry Browning is a Professor at South Dakota State University. Contact: Larry.Browning@sdstate.edu

\section{Suggested citation:}

Durr, T., Kampmann, J., Hales, P., \& Browning, L. (2020). Lessons learned from online PLCs of rural STEM teachers. The Rural Educator, 41(1), 20-26. https://doi.org/10.35608/ruraled.v41i1.555 